\title{
Cytogenetic analyses in Trinomys (Echimyidae, Rodentia), with description of new karyotypes
}

\author{
Naiara Pereira Araújo ${ }^{\text {Corresp., }}{ }^{1}$, Cayo Augusto Rocha Dias ${ }^{1}$ ， Rodolfo Stumpp ${ }^{1}$, Marta Svartman ${ }^{\text {Corresp. } 1}$ \\ 1 Departamento de Biologia Geral, Universidade Federal de Minas Gerais, Belo Horizonte, Minas Gerais, Brazil \\ Corresponding Authors: Naiara Pereira Araújo, Marta Svartman \\ Email address: naiaraparaujo@yahoo.com.br, svartmanm@ufmg.br
}

Trinomys Thomas (1921) is a terrestrial genus of spiny rats endemic to Brazilian areas of Atlantic Forest and transitional areas of Cerrado and Caatinga. Although most species have been already karyotyped, the available cytogenetic information is mostly restricted to diploid and fundamental numbers. We analyzed the chromosomes of two Trinomys species: $T$. moojeni $(2 \mathrm{n}=56, \mathrm{FN}=106)$ and $T$. setosus setosus $(2 \mathrm{n}=56, \mathrm{FN}=106$ and $2 \mathrm{n}=56$, $\mathrm{FN}=108$ ). Our analyses included GTG- and CBG-banding, silver-staining of the nucleolar organizer regions, and chromosome mapping of telomeres and 45S rDNA by fluorescent in situ hybridization (FISH). Comparative GTG- and CBG-banding suggested that the interspecific variation may be due to rearrangements such as pericentric inversions, centromere repositioning, and heterochromatin variation. We report two new karyotypes for Trinomys s. setosus and describe for the first time the banding patterns of the two Trinomys species. 
1 Title: Cytogenetic analyses in Trinomys (Echimyidae, Rodentia), with description of new

2 karyotypes

3 Naiara Pereira Araújo*, Cayo Augusto Rocha Dias, Rodolfo Stumpp, and Marta Svartman*

4 Departamento de Biologia Geral, Universidade Federal de Minas Gerais, Belo Horizonte, Minas

5 Gerais, Brazil.

$6 *$ Corresponding author:

$7 \quad$ Naiara Pereira de Araújo

8 E-mail address: naiaraparaujo@yahoo.com.br

9 Marta Svartman

E-mail address: svartmanm@ufmg.br

12 Abstract

13 Trinomys Thomas (1921) is a terrestrial genus of spiny rats endemic to Brazilian areas of

14 Atlantic Forest and transitional areas of Cerrado and Caatinga. Although most species have been

15 already karyotyped, the available cytogenetic information is mostly restricted to diploid and

16 fundamental numbers. We analyzed the chromosomes of two Trinomys species: T. moojeni

$17(2 \mathrm{n}=56, \mathrm{FN}=106)$ and $T$. setosus setosus $(2 \mathrm{n}=56, \mathrm{FN}=106$ and $2 \mathrm{n}=56, \mathrm{FN}=108)$. Our analyses

18 included GTG- and CBG-banding, silver-staining of the nucleolar organizer regions, and

19 chromosome mapping of telomeres and 45S rDNA by fluorescent in situ hybridization (FISH).

20 Comparative GTG- and CBG-banding suggested that the interspecific variation may be due to

21 rearrangements such as pericentric inversions, centromere repositioning, and heterochromatin

22 variation. We report two new karyotypes for Trinomys s. setosus and describe for the first time

23 the banding patterns of the two Trinomys species. 


\section{Introduction}

Spiny rats (family Echimyidae) are the most diverse group of South American hystricognath rodents. There are 22 extant genera and around 90 species found from Central America to Northern Argentina, where they have radiated across multiple biomes, including a vast array of ecomorphological adaptations, encompassing arboreal, semi-fossorial, terrestrial, and semiaquatic lifestyles (Emmons, Leite \& Patton, 2015). The great variation in their life history, adaptations, and morphotypes also extends to their karyotypes. Their diploid numbers (2n) range from 2n=14 in Proechimys gr. longicaudatus (Amaral et al., 2013) to $2 n=118$ in the arboreal species Dactylomys boliviensis (Dunnum, Salazar-Bravo \& Yates, 2001), which has the highest 2n known among mammals. This variation results from the presence of B-chromosomes (Yonenaga-Yassuda et al., 1985; Fagundes, Camacho \& Yonenaga-Yassuda, 2004), multiple sex chromosome systems (Amaral et al., 2013; Costa et al., 2016), and several rearrangements, including inversions, fusions/fissions, and constitutive heterochromatin variation. The great karyotypic variability observed in Echimyidae represents an opportunity to elucidate mechanisms of chromosome evolution and their role during speciation and diversification. Within Echimyidae, the Atlantic spiny rats of the genus Trinomys Thomas, 1921, allocated within Euryzygomatomyinae (Lara \& Patton, 2000; Fabre et al., 2017), are amongst the most taxonomically complex genera. Trinomys comprises ten extant species endemic to Brazilian areas of Atlantic Forest and transitional areas of Cerrado and Caatinga (Pessôa et al., 2015). Most species have few morphological synapomorphies, with many primitive and few derived features (Dalapicolla \& Leite, 2015), which led different authors to consider several of them as subspecies in different taxonomic arrangements (Lara, Patton \& Silva, 1996; Lara \& Patton, 
47 2000; Pessôa et al., 2015). Three species, T. eliasi, T. moojeni, and T. yonenagae, are considered

48 near threatened or endangered due to forest fragmentation and habitat destruction (IUCN, 2018).

49

50

51

52

53

54

55
As for most rodents, Trinomys presents a confusing taxonomic history. Until 1996, it was considered a subgenus of Proechimys due to craniodental and body similarities (Moojen, 1948;

Lara, Patton \& Silva, 1996). Trinomys was then raised to a generic level after studies including biogeographic data, dental characters, and mitochondrial DNA sequence-based phylogenies (Lara, Patton \& Silva, 1996; Lara \& Patton, 2000; Carvalho \& Salles, 2004). More recently molecular phylogenetic studies with mitochondrial and nuclear sequences strongly supported Trinomys as a sister taxon to Clyomys and Euryzygomatomys, excluding its relationship with Proechimys (Fabre et al., 2012, 2017; Upham \& Patterson, 2012).

The karyotypes of all recognized species of Trinomys have already been described, with the exception of T. mirapitanga (Table 1). Nevertheless, most reported cytogenetic data are restricted to the description of the $2 \mathrm{n}$ and fundamental numbers $(\mathrm{FN})$, without information on banding patterns or FISH. The $2 \mathrm{n}$ ranges from $2 \mathrm{n}=54$ in $T$. yonenagae to $2 \mathrm{n}=60$ in $T$. albispinus, T. dimidiatus, and T. iheringi (Table 1). Some specimens of T. iheringi presented a higher $2 \mathrm{n}$ due to the presence of minute supernumerary chromosomes (Yonenaga-Yassuda et al., 1985; Fagundes, Camacho \& Yonenaga-Yassuda, 2004). Comparisons of the GTG-banded chromosomes of $T$. iheringi, $T$. albispinus minor $(2 \mathrm{n}=60, \mathrm{FN}=116)$, and $T$. yonenagae $(2 \mathrm{n}=54$, FN=104), the only Trinomys species analyzed after banding, revealed very conserved karyotypes (Leal-Mesquita et al., 1992). Closely related species of Trinomys seem to share the same karyotype, as is the case of the sister taxa $T$. paratus and $T$. eliasi (both with $2 \mathrm{n}=58, \mathrm{FN}=112$ ), and of $T$. dimidiatus and $T$. iheringi (both with $2 \mathrm{n}=60, \mathrm{FN}=116$ ). In fact, it has been suggested 
that the divergence time among Trinomys species was not sufficient to produce great karyotypic changes (Souza, Corrêa \& Pessôa, 2006; Lazar et al., 2017).

We comparatively analyzed the karyotypes of Trinomys moojeni and T. setosus setosus, including GTG- and CBG-banding, silver staining of the nucleolar organizer regions (AgNORs), and FISH with telomeric and 45S rDNA probes. Two new karyotypes are described for Trinomys s. setosus and this is the first description of banding patterns for both species.

\section{Material and Methods}

We studied five specimens of Trinomys, collected in the state of Minas Gerais, southeastern Brazil (Table 2), under the permits provided by the Instituto Chico Mendes de Conservação da Biodiversidade (ICMBio; permit number 22279-1 to Beatriz Dias Amaro) and the Instituto Brasileiro do Meio Ambiente e dos Recursos Naturais Renováveis (SISBIO-IBAMA; permit numbers 12989-2 and 36574-1, conceded to Adriano Pereira Paglia and Fabíola Keesen Ferreira, respectively). The conducted research was approved by the Ethics Committee in Animal Experimentation (CEUA) of Universidade Federal de Minas Gerais (approval number: 211/2013). Voucher specimens were deposited in the Museu de Ciências Naturais da Pontifícia Universidade Católica de Minas Gerais (MCN-M, Minas Gerais, Brazil) or in the Centro de Coleções Taxonômicas da Universidade Federal de Minas Gerais (CCT-UFMG, Minas Gerais, Brazil). Morphological identification was based on skull, dental and skin characters described by Moojen (1948), Iack-Ximenes (2005), Dalapiccola \& Leite (2015) and Pessôa et al. (2015). The morphological diagnosis of each specimen is given in Supplemental Table S1. We plotted the sampling sites of the specimens used in this study against the known range of Trinomys species 
91 using QGIS 2.18.16 (Fig. 1; QGIS Development Team, 2018). Spatial datasets containing the

92 known range of Trinomys species were obtained from IUCN (IUCN, 2018).

93 Chromosome preparations were obtained directly from bone marrow (Ford \& Hamerton, 1956).

94 GTG- and CBG-banding patterns and silver-staining of the nucleolar organizer regions (Ag-

95 NORs) were performed according to Seabright (1971), Sumner (1972), and Howell \& Black

96 (1980), respectively. FISH with a biotinylated telomeric sequence (Invitrogen) and with the R2

97 45S rDNA probe labeled by nick translation with digoxigenin-11-dUTP (DIG-Nick Translation

98 mix, Roche Applied Science), followed Araújo et al. (2017) and Araújo et al. (2014),

99 respectively. Immunodetection was carried out with neutravidin and antidigoxigenin, both

100 conjugated with rhodamine (Roche Applied Science). The analyses and image acquisition were

101 performed under a Zeiss Axioimager 2 epifluorescence microscope using the AxioVision

102 software (Zeiss), Adobe Photoshop CS3 Extended was used for image edition. For each

103 specimen, at least 20 metaphases of each experiment were analyzed.

104 Ordination and phylogenetic methods were employed in order to check the assignment of MCN-

M 2587, MCN-M 3296, and MCN-M 3297 to T. setosus. In order to do this, we sequenced the 106 $401 \mathrm{bp}$-long segment of the mitochondrial cytochrome $b$ (cyt $b$ ) of each specimen and included sequences from nine Trinomys species retrieved from GenBank in a phylogenetic analysis. The sequences of the specimens MCN-M2816 (T. moojeni) and UFMG 6024 (T. s. setosus) were previously deposited in GenBank after assembly of their mitochondrial genomes (Araújo et al., 2016). Euryzygomatomys spinosus, Fischer, 1814, was used as outgroup. Total genomic DNA of each Trinomys specimen was extracted from liver and their cyt $b$ was amplified by polymerase chain reaction (PCR) with primers MVZ 05 and MVZ 04 (Smith \& Patton, 1993). The PCR

113 products were purified using the Wizard SV Gel and PCR Clean-up System kit (Promega) and 
114 sequenced on the ABI3130 platform (Myleus Biotechnology). The GenBank accession numbers

115 of the sequences generated in this study, as well as those included in the analyses are presented

116 in the Supplemental Material (Part B).

117 The sequences obtained and those from GenBank were aligned using the Muscle (Edgar, 2004)

118 algorithm. MEGA 7 (Kumar, Stecher \& Tamura, 2016) was used to build a Kimura-2-parameter 119 corrected distance matrix in which our ordination analysis was based. Ordination methods were 120 used since they are useful tools to perform dimensionality reduction and to represent the distance 121 between sequences in a coordinate (Cartesian) space where the distances are preserved (Higgins, 122 1992; Ramette, 2007; Zhang et al., 2011). Principal Coordinate Analysis (PCoA) was used to explore the similarity among our specimen's sequences and other Trinomys species. The analysis

124 was conducted in R (R Core Team, 2017) using the "pcoa" function in package APE (Paradis, 125 Claude \& Strimmer, 2004) and Lingoes procedure for correcting for negative eigenvalues.

126 Phylogenetic relatedness was used as a way of determining the most probable identity of the 127 subject sequences. Thus, two methods of phylogenetic reconstruction were employed: maximum 128 likelihood (ML) and bayesian inference (BI), which were carried out in RaxML 8 (Stamatakis, 129 2014) and MrBayes 3.2 (Ronquist et al., 2012), respectively. ML search comprised optimizations over 100 randomized maximum parsimony starting trees using the rapid hill-climbing algorithm under the GTRGAMMA model. As a measure of branch support, information on frequencies of 1000 replicates of non-parametric bootstrap were annotated on the best-scoring ML tree. Bayesian inference comprised two independent runs composed of four chains each. A reversible jump MCMC sampling was used in order to explore different substitution schemes. Parameters and trees were sampled every 1000 generations along a total of 20 million generations. After

136 discarding a quarter of samples as burn-in, parameters and trees were summarized and the 
137 following metrics were used to assess MCMC convergence: standard deviation of split

138 frequencies, effective sample size and potential scale reduction factor for each parameter.

\section{Results}

141 Bayesian inference and ML trees recovered Trinomys as monophyletic and grouped MCN-M

1422816 within T. moojeni and the specimens UFMG 6024, MCN-M 2587, MCN-M 3296, and

143 MCN-M 3297 within T. setosus (Fig. 2; Supplemental Figs. S1 and S2). This was further

144 supported by the PCoA results, that showed samples of the same species clustering together on

145 the graph (Supplemental Fig. S3). Morphological characters analyses corroborated the phylogeny

146 and allowed assigning the T. setosus specimens as T. s. setosus (Supplemental Table S1).

147 The female $T$. moojeni had a complement with $2 \mathrm{n}=56$ and $\mathrm{FN}=106$, similar to that described by

148 Corrêa et al. (2005), composed of 26 pairs of biarmed (pairs 1-26) and one pair of acrocentric

149 (pair 27) autosomes, and submetacentric X chromosomes (Fig. 3). The autosomes of the female

150 Trinomys s. setosus $(2 \mathrm{n}=56, \mathrm{FN}=106)$ collected in Serro included 26 biarmed pairs decreasing in

151 size from large to small (pairs 1-25 and 27) and a small acrocentric pair (pair 26). The X

152 chromosomes were large acrocentrics (Fig. 4A). The other three specimens of T. s. setosus had

153 karyotypes with $2 \mathrm{n}=56$ and $\mathrm{FN}=108$ (Fig. 4C and Supplemental Fig. S4), similar to the other

154 cytotype of $T$. s. setosus, but with pair 26 as a biarmed element. Their X chromosome was a large

155 acrocentric and the Y was a small acrocentric (Fig. 4 and Supplemental Fig. S4).

156 After GTG-banding, it was possible to identify all chromosomes of each species (Figs. 3A and 4)

157 and to verify that the complements of $T$. s. setosus with FN=106 and FN=108 (Fig. 5) differed in

158 relation to pair 26, which was acrocentric or biarmed, in the animals with $\mathrm{FN}=106$ and $\mathrm{FN}=108$,

159 respectively. CBG-banding revealed weak centromeric constitutive heterochromatin in pairs 1-5, 
$1609,10,15,17-27$, and the X chromosome of T. moojeni (Fig. 3B); pairs 1, 11, 15, 16, 19-27, and

161 the $\mathrm{X}$ chromosome of $T$. s. setosus $(2 \mathrm{n}=56, \mathrm{FN}=106$; Fig. $4 \mathrm{~B})$; and pairs $1,6,8,16,18-27$, and

162 the sex chromosomes of $T$. s. setosus $(2 \mathrm{n}=56, \mathrm{FN}=108$; Fig. 4D). Both species had a large

163 interstitial secondary constriction on the long arm of pair 6, which bears the NORs (Fig. 6).

164 Hybridization with the telomeric probe showed signals only at the termini of all chromosomes of 165 the two species studied (Fig. 6C, F, and I).

166

\section{Discussion}

168 The interspecific grouping of Trinomys, recovered by the phylogenetic analyses, was congruent with previous studies (Lara \& Patton, 2000; Tavares, Pessôa \& Seuánez, 2015; Lazar et al., 170 2017). Our phylogenetic analysis is also supported by the specimens' distribution (Fig. 1), morphology (Supplemental Table S1) and karyotypes. The collecting locality of T. moojeni

172 (MCN-M 2816), Serra do Caraça Private Reserve, is the same of the specimens studied by 173 Cordeiro-Júnior \& Talamoni (2006) and the karyotype was similar to that described for this 174 species (Corrêa et al. 2005; Fig. 3). Trinomys setosus setosus, in turn, which occurs from the 175 coastal area of the Brazilian states of Sergipe, Bahia, and Espírito Santo to the interior of Minas 176 Gerais (Pessôa et al. 2015), were collected in three municipalities of Minas Gerais.

177 A comparison of the GTG-banded chromosomes of $T$. moojeni and T. s. setosus $(2 \mathrm{n}=56$, 178 FN=106) evidenced very similar karyotypes. They mainly differed on their pairs 2, 27, and X 179 chromosomes, possibly due to inversions and/or centromere repositioning (Fig. 5). In order to 180 establish the exact mechanisms involved, further experiments including FISH with specific 181 sequences from the regions of interest are necessary. 
182 The karyotypes described herein for T. s. setosus differed in 2n, FN, and/or the sex chromosome

183 morphology from those already published for this genus (Yonenaga-Yassuda et al., 1985; Leal-

184 Mesquita et al., 1992; Corrêa et al., 2005; Pessôa et al., 2005; Souza, Corrêa \& Pessôa, 2006;

185 Lazar et al., 2017; Table 1). Trinomys gratiosus bonafidei also has 2n=56 and FN=108, but

186 differently from our specimens, has a metacentric Y chromosome (Pessôa et al., 2005). The most

187 recent revision on Trinomys divided T. setosus into the subspecies T. s. setosus and T. s. elegans

188 (Pessôa et al., 2015). The diploid number was reported only for T. s. elegans and without

189 banding patterns $(2 \mathrm{n}=56, \mathrm{FN}=104$; Corrêa et al. 2005). Pessôa et al. (2015) mentioned that the

190 karyotype of T. s. setosus from Almenara, Minas Gerais state, has $2 \mathrm{n}=56$ and $\mathrm{FN}=108$, but no

191 figure was provided. Our T. s. setosus had karyotypes with FN=106 and 108 and differed from

192 that described by Corrêa et al. (2005) by the presence of additional short arms on pair 27 and

193 pairs 26 and 27 of our specimens, respectively. These differences may be real or may reflect

194 variations in chromosome condensation between both samples, as poorly elongated small

195 chromosomes could prevent the detection of short arms. If real, these differences between $T . s$.

196 setosus and T. s. elegans may be correlated with their subspecies allocation or may be due to

197 interpopulational variation, as seems to be the case of $T$. s. setosus. Our phylogenetic analyses

198 did not distinguish between T. s. setosus and T. s. elegans (Fig. 2, Supplemental Fig. S1 and S2),

199 but the morphological analysis allowed to recognize these subspecific taxa. The karyotype

200 information was also relevant in species identification, revealing karyotypes that differed from

201 those of other species of the genus.

202 The T. s. setosus karyotypes described herein also differed from others previously reported for

203 Trinomys in the morphology of the X chromosome. With the exception of $T$. setosus and $T$.

204 yonenagae, which presented acrocentric X chromosomes, all Trinomys species had a 
205 submetacentric X (T. albispinus, T. dimidiatus, T. eliasi, T. gratiosus, T. iheringi, T. moojeni,

206 and T. paratus). Based on our cytochrome $b$ phylogeny (Fig. 2), we suggest that a pericentric

207 inversion or a centromere shift on the X chromosome occurred in the lineage that gave rise to $T$.

208 setosus and T. yonenagae. The change in X chromosome morphology in the common ancestor of

209 both species may be related to karyotype differentiation from other taxa and reproductive

210 isolation. It has been suggested that chromosome rearrangements may affect chromatin structure

211 (Johnson \& Lachance, 2012) and, consequently, play a role in hybrid incompatibility. The

212 change in gene expression after chromosome rearrangements was also suggested to contribute to

213 the speciation process (Potter et al., 2017).

214 Our specimens and all the other species of the genus analyzed after CBG-banding, (T. albispinus

215 minor, T. iheringi, T. paratus, and T. yonenagae) exhibited faint heterochromatic blocks on

216 centromeric regions, mainly located on the smallest autosomes and the sex chromosomes

217 (Yonenaga-Yassuda et al., 1985; Leal-Mesquita et al., 1992; Fagundes, Camacho \& Yonenaga-

218 Yassuda, 2004; Lazar et al., 2017). Interestingly, both cytotypes of T. s. setosus differed in

219 heterochromatin distribution (Fig. 4), which may be involved in the chromosome evolution of

220 this taxon.

221 Trinomys moojeni and T. s. setosus had a large interstitial secondary constriction on the long arm

222 of pair 6, which bears the NORs (Fig. 6). A chromosome pair with a large secondary constriction

223 bearing the single NOR is a marker of echimyids, as already reported for T. iheringi and other

224 Echimyidae genera (Fagundes, Camacho \& Yonenaga-Yassuda, 2004; Silva et al., 2012; Araújo

225 et al., 2014). The comparison of the GTG-banded karyotypes suggests that the NOR-bearing

226 chromosome is the same in our specimens and in T. albispinus, T. iheringi, and T. yonenagae 
227 (Leal-Mesquita et al., 1992; Fagundes, Camacho \& Yonenaga-Yassuda, 2004) and is probably

228 conserved in the genus.

229 Hybridization with the telomeric probe showed signals only at the extremities of all

230 chromosomes (Fig. 6C, F, and I). This pattern of hybridization was similar to that described for

231 T. iheringi (Fagundes, Camacho \& Yonenaga-Yassuda, 2004). Bolzán (2017) suggested that the

232 absence of interstitial telomeric sequences indicates the evolutionary status of the chromosomes

233 of a species. Accordingly, species without or with only a few interstitial telomeric sequences

234 would have more conserved chromosomes, as seems to be the case of Trinomys.

\section{Conclusions}

237 In summary, based on the available data, it is clear that Trinomys species present conserved 238 karyotypes with small variation in diploid numbers $(2 n=54$ to $2 n=61-65)$ and mostly composed

239 of biarmed autosomes. The X chromosomes are usually large submetacentrics and all the species

240 analyzed presented one marker chromosome pair with a secondary constriction corresponding to

241 the NOR, which is also typical for the other echimyid genera. The great conservation extends to

242 the GTG- and CBG-banding patterns in the few species which had these patterns described. As

243 previously proposed by Leal-Mesquita et al. (1992), pericentric inversions, centromere

244 repositioning, and other minor rearrangements seem to be responsible for the chromosome

245 evolution in this genus. Further analyses, including a robust phylogenetic hypothesis, cytogenetic

246 studies with high resolution banding patterns and molecular data of a larger array of Trinomys

247 species, are needed to improve our understanding of the chromosome evolution and genome

248 organization of this genus. It should be stressed that Trinomys species, especially those from

249 Minas Gerais, need more thorough morphological and molecular analyses, as their cytogenetic 
250 information alone is insufficient for taxonomic identification. In fact, several different species

251 present very similar karyotypes (Lazar et al., 2017).

252

253 Acknowledgements

254 The authors are indebted to Adriano Pereira Paglia, Beatriz Dias Amaro, Flávia Nunes Vieira, 255 and Karla Leal who provided us with Trinomys material.

256

\section{References}

258 Amaral PJS, Nagamachi CY, Noronha RCR, Costa MJR, Pereira AL, Rossi RV, Mendes-

259 Oliveira AC, Pieczarka JC. 2013. Proechimys (Rodentia, Echimyidae): characterization and

260 taxonomic considerations of a form with a very low diploid number and a multiple sex

261 chromosome system. BMC Genetics 14:21. DOI: 10.1186/1471-2156-14-21.

262 Araújo NP, Loss, AC, Cordeiro-Junior DA, Silva KR, Leite YLR, Svartman M. 2014. New

263 karyotypes of Atlantic tree rats, genus Phyllomys (Rodentia: Echimyidae). Genome 57:1-8. DOI:

264 10.1139/gen-2013-0168.

265 Araújo NP, Dias GB, Amaro BD, Kuhn GCS, Svartman M. 2016. The complete mitochondrial

266 genomes of two Atlantic spiny rats, genus Trinomys (Rodentia: Echimyidae), from low-pass

267 shotgun sequencing. Gene Reports 5:18-22. DOI: 10.1016/j.genrep.2016.08.003

268 Araújo NP, Kuhn GCS, Nunes FV, Morcatty T, Paglia AP, Svartman M. 2017. Comparative

269 genomic in situ hybridization and the possible role of retroelements in the karyotypic evolution

270 of three Akodontini species. International Journal of Genomics. DOI: 10.1155/2017/5935380.

271 Bolzán AD. 2017. Interstitial telomeric sequences in vertebrate chromosomes: origin, function,

272 instability and evolution. Mutation Research 773:51-65. DOI: 10.1016/j.mrrev.2017.04.002. 
273 Carvalho GAS, Salles LO. 2004. Relationships among extant and fossil echimyids (Rodentia:

274 Hystricognathi). Zoological Journal of the Linnean Society 142:445-477. DOI: 10.1111/j.1096$275 \quad 3642.2004 .00150 . x$.

276 Cordeiro-Júnior DA, Talamoni SA. 2006. New data on the life history and occurrence of spiny 277 rats Trinomys moojeni (Rodentia: Echimyidae), in southeastern Brazil. Acta Theriologica 278 51:163-168. DOI: 10.1007/BF03192667.

279 Corrêa MMO, Lopes MOG, Câmara EVC, Oliveira LC, Pessôa LM. 2005. The karyotypes of 280 Trinomys moojeni (Pessôa, Oliveira \& Reis, 1992) and Trinomys setosus elegans (Lund, 1841) 281 (Rodentia, Echimyidae) from Minas Gerais, Eastern Brazil. Arquivos do Museu Nacional $28263: 169-174$.

283 Costa MJR, Amaral PJS, Pieczarka JC, Sampaio MI, Rossi RV, Mendes-Oliveira AC, Noronha 284 RCR, Nagamachi CY. 2016. Cryptic species in Proechimys goeldii (Rodentia, Echimyidae)? A 285 case of molecular and chromosomal differentiation in allopatric populations. Cytogenetic and 286 Genome Research 148:199-210. DOI: 10.1159/000446562.

287 Dalapicolla J, Leite YLR. 2015. Taxonomic implications of morphological variation in three 288 species of Trinomys (Rodentia: Echimyidae) from eastern Brazil. Zootaxa 3919:61-80. DOI: 289 10.11646/zootaxa.3919.1.3.

290 Dunnum JL, Salazar-Bravo J, Yates TL. 2001. The Bolivian bamboo rat, Dactylomys boliviensis 291 (Rodentia: Echimyidae), a new record for chromosome number in a mammal. Mammalian 292 Biology 66:121-126.

293 Edgar RC. 2004. MUSCLE: a multiple sequence alignment method with reduced time and space 294 complexity. BMC Bioinformatics 5:113. DOI: 10.1186/1471-2105-5-113. 
295 Emmons LH, Leite YLR, Patton JL. 2015. Family Echimyidae. In: Patton JL, Pardiñas UFJ, 296 D'Elía G, eds. Mammals of South America - Rodents. Chicago: University of Chicago Press, $297877-880$.

298 Fabre P, Galewski T, Tilak M, Douzery EJP. 2012. Diversification of South American spiny rats 299 (Echimyidae): a multigene phylogenetic approach. Zoologica Scripta 42:117-134. DOI:

300 10.1111/j.1463-6409.2012.00572.x.

301 Fabre P, Upham NS, Emmons LH, Justy F, Leite YLR, Loss AC, Orland L, Tilak M, Patterson 302 BD, Douzery EJP. 2017. Mitogenomic phylogeny, diversification, and biogeography of South 303 American spiny rats. Molecular Biology and Evolution 34:613-633. DOI:

304 10.1093/molbev/msw261.

305 Fagundes V, Camacho JPM, Yonenaga-Yassuda Y. 2004. Are the dot-like chromosomes in 306 Trinomys iheringi (Rodentia, Echimyidae) B chromosomes?. Cytogenetic and Genome Research 307 106:159-164. DOI: 10.1159/000079282.

308 Ford CE, Hamerton JL. 1956. A colchicine, hypotonic citrate, squash sequence for mammalian 309 chromosomes. Stain Technology 31:247-251. DOI: 10.3109/10520295609113814.

310 Higgins DG. 1992. Sequence ordinations: a multivariate analysis approach to analysing large 311 sequence data sets. Computer Applications in the Biosciences 8:15-22. DOI:

312 10.1093/bioinformatics/8.1.15.

313 Howel WM, Black DA. 1980. Controlled silver-staining of nucleolus organizer regions with a 314 protective colloidal developer: a 1-step method. Experientia 36:1014-1015. DOI:

315 10.1007/BF01953855.

316 Iack-Ximenes GE. 2005. Revisão de Trinomys Thomas, 1921 (Rodentia, Echimyidae). Thesis, 317 Universidade de São Paulo. 
318 IUCN. 2018. The IUCN Red List of Threatened Species. Version 2017.3 IUCN. Available at

319 www.iucnredlist.org (accessed 23 February 2018).

320 Johnson NA, Lachance J. 2012. The genetics of sex chromosomes: evolution and implications

321 for hybrid incompatibility. Annals of the New York Academy of Sciences 1256:E1-E22. DOI:

$32210.1111 / \mathrm{j} .1749-6632.2012 .06748 . \mathrm{x}$

323 Kumar S, Stecher G, Tamura K. 2016. MEGA7: Molecular Evolutionary Genetics Analysis

324 Version 7.0 for Bigger Datasets. Molecular Biology and Evolution 33:1870-1874. DOI:

325 10.1093/molbev/msw054.

326 Lara MC, Patton JL, Silva MNF. 1996. The simultaneous diversification of South American

327 echimyid rodents (Hystricognathi) based on complete cytochrome $b$ sequences. Molecular

328 Phylogenetics and Evolution 5:403-413. DOI: 10.1006/mpev.1996.0035.

329 Lara MC, Patton JL. 2000. Evolutionary diversification of spiny rats (genus Trinomys, Rodentia:

330 Echimyidae) in the Atlantic Forest of Brazil. Zoological Journal of the Linnean Society 130:661-

331 686. DOI: $10.1006 /$ zjls.2000.0240.

332 Lazar A, Nacif C, Weksler M, Bonvicino CR. 2017. The karyotype of Trinomys paratus

333 (Rodentia: Echimyidae) with comments about its phylogenetic relationship. Mammalia 82:93-98.

334 DOI: 10.1515/mammalia-2016-0131.

335 Leal-Mesquita ER, Yonenaga-Yassuda Y, Chu TH, Rocha PLB. 1992. Chromosomal

336 characterization and comparative cytogenetic analysis of two species of Proechimys

337 (Echimyidae, Rodentia) from the Caatinga domain of the state of Bahia, Brazil. Caryologia

338 43:197-212. DOI: 10.1080/00087114.1992.10797223.

339 Moojen J. 1948. Speciation in the Brazilian spiny rats (genus Proechimys, family Echimyidae).

340 Lawrence: University of Kansas Publications of the Museum of Natural History. 
341 Paradis E, Claude J, Strimmer K. 2004. APE: analyses of phylogenetics and evolution in R

342 language. Bioinformatics 20:289-290. DOI: 10.1093/bioinformatics/btg412.

343 Pessôa LM, Corrêa MMO, Bitencourt E, Reis SF. 2005. Chromosomal characterization of taxa

344 of the genus Trinomys Thomas, 1921, (Rodentia: Echimyidae) in the states of Rio de Janeiro and

345 São Paulo. Arquivos do Museu Nacional 63:161-168.

346 Pessôa LM, Tavares WC, Oliveira JA, Patton JL. 2015. Genus Trinomys Thomas, 1921. In:

347 Patton JL, Pardiñas UFJ, D'Elía G, eds. Mammals of South America - Rodents. Chicago:

348 University of Chicago Press, 999-1019.

349 Potter S, Bragg JG, Blom MPK, Deakin JE, Kirkpatrick M, Eldridge MDB, Moritz C. 2017.

350 Chromosomal speciation in the genomics era: disentangling phylogenetic evolution of rock-

351 wallabies. Frontiers in Genetics 8:10. DOI: 10.3389/fgene.2017.00010

352 QGIS DevelopmentTeam. 2018. QGIS Geographic Information System. Open Source Geospatial

353 Foundation Project. Available at http://qgis.osgeo.org (accessed 08 May 2018).

354 R Core Team. 2017. R: A Language and Environment for Statistical Computing.

355 Ramette A. 2007. Multivariate analyses in microbial ecology. FEMS Microbiology Ecology

356 62:142-160. DOI: 10.1111/j.1574-6941.2007.00375.x.

357 Ronquist F, Teslenko M, Van Der Mark P, Ayres DL, Darling A, Höhna S, Larget B, Liu L,

358 Suchard MA, Huelsenbeck JP. 2012. Mrbayes 3.2: Efficient bayesian phylogenetic inference and 359 model choice across a large model space. Systematic Biology 61:539-542. DOI:

$360 \quad 10.1093 /$ sysbio/sys029.

361 Seabright M. 1971. A rapid banding technique for human chromosomes. Lancet 298:971-972.

362 DOI: 10.1016/S0140-6736(71)90287-X. 
363 Silva CEF, Eler ES, Silva MNF, Feldberg E. 2012. Karyological analysis of Proechimys cuvieri

364 and Proechimys guyannensis (Rodentia, Echimyidae) from central Amazon. Genetetics and

365 Molecular Biology 35:88-94. DOI: 10.1590/S1415-47572012005000007.

366 Smith MF, Patton JL. 1993. The diversification of South American murid rodents: evidence from

367 mitochondrial DNA sequence data for the akodontine tribe. Biological Journal of the Linnean

368 Society 50:149-177. DOI: 10.1111/j.1095-8312.1993.tb00924.x.

369 Souza ALG, Corrêa MMO, Pessôa LM. 2006. Morphometric discrimination between Trinomys

370 albispinus (Is. Geoffroy, 1838) and Trinomys minor (Reis e Pessôa, 1995) from Chapada

371 Diamantina, Bahia, Brazil, and the karyotype of Trinomys albispinus (Rodentia, Echimyidae).

372 Arquivos do Museu Nacional 64:325-332.

373 Stamatakis A. 2014. The RAxML v8. 0. X Manual 1-55.

374 Sumner AT. 1972. A simple technique for demonstrating centromeric heterochromatin.

375 Experimental Cell Research 75:304-306. DOI: 10.1016/0014-4827(72)90558-7.

376 Tavares WC, Pessôa LM, Seuánez HN. 2015. Plio-Pleistocene history of the endangered spiny

377 rat Trinomys eliasi (Echimyidae) from Rio de Janeiro, Brazil. Journal of Mammalogy 96:94-106.

378 DOI: 10.1093/jmammal/gyu010.

379 Upham NS, Patterson BD. 2012. Diversification and biogeography of the neotropical

380 caviomorph lineage Octodontoidea (Rodentia: Hystricognathi). Molecular Phylogenetics and

381 Evolution 63:417-429. DOI: 10.1016/j.ympev.2012.01.020.

382 Yonenaga-Yassuda Y, Souza MJ, Kasahara S, L’Abbate M, Chu HT. 1985. Supernumerary

383 system in Proechimys iheringi iheringi (Rodentia, Echimyidae), from the state of São Paulo,

384 Brazil. Caryologia 38:179-194. DOI: 10.1080/00087114.1985.10797742. 
385 Zhang J, Mamlouk AM, Martinetz T, Chang S, Wang J, Hilgenfeld R. 2011. PhyloMap: an 386 algorithm for visualizing relationships of large sequence data sets and its application to the 387 influenza A virus genome. BMC Bioinformatics 12:248. DOI: 10.1186/1471-2105-12-248. 


\section{Legends to Figures:}

389 Figure 1 - Sample sites of the specimens used in this study against the known range of Trinomys species. For detailed references on spatial data downloaded from IUCN for each species, see

391

392

Supplemental Material (Part A). Distribution of (A) T. dimidiatus, T. paratus, T. setosus, and T, yonenagae, and (B) T. albispinus, T. eliasi, T. gratiosus, T. iheringi, T. mirapitanga, and T. moojeni. Triangles represent our specimens and circles indicate the specimens whose mitochondrial sequences were retrieved from GenBank.

Figure 2 - Collapsed bayesian inference tree based on a 401-bp fragment of the cytochrome $b$ gene from species of Trinomys. Euryzygomatomys spinosus was used as outgroup. Collection sites: (A) Serra do Caraça Private Reserve/MG, (B) Morro do Pilar/MG, (C) Serro/MG, (D) São Gonçalo do Rio Abaixo/MG. Numbers represent Bayesian posterior probabilities $\geq 0.95$. Specimens included in this study are in bold. See Supplemental Fig. S1 for specimens details of the collapsed branches. Scale bar represents the number of substitutions per site.

Figure 3 - Karyotypes of a female Trinomys moojeni $(2 \mathrm{n}=56, \mathrm{FN}=106)$ from Serra do Caraça Private Reserve, Minas Gerais State, after (A) GTG- and (B) CBG-banding. Scale bar $=10 \mu \mathrm{m}$. Figure 4 - Karyotypes of Trinomys setosus setosus: a female with 2n=56, FN=106 (A and B) from Serro, Minas Gerais state, and of a male with 2n=56, FN=108 (C and D) from São Gonçalo do Rio Abaixo, Minas Gerais state, after GTG- (A and C) and CBG-banding (B and D). Scale bar $=10 \mu \mathrm{m}$

Figure 5 - Comparison of GTG-banded chromosomes of Trinomys species. Chromosomes from the left to the right: Trinomys moojeni $(2 \mathrm{n}=56, \mathrm{FN}=106)$, Trinomys setosus setosus with $2 \mathrm{n}=56$, $\mathrm{FN}=106$, and with $2 \mathrm{n}=56, \mathrm{FN}=108 . *$ = centromere position. The arrows indicate possible inversion breakpoints. 
411 Figure 6 - Cells of Trinomys species after Ag-NOR, FISH with the 45S rDNA, and telomeric

412 probe (Tel). Metaphases of $(\mathrm{A}-\mathrm{C})$ a female $T$. moojeni $(2 \mathrm{n}=56, \mathrm{FN}=106),(\mathrm{D}-\mathrm{F})$ a female $T$.

413 setosus setosus $(2 \mathrm{n}=56, \mathrm{FN}=106)$, and $(\mathrm{G}-\mathrm{I})$ a male $T$. s. setosus $(2 \mathrm{n}=56, \mathrm{FN}=108)$. In the insets

414 (A, D, and G), pair 6 after Giemsa staining. Note the secondary constrictions. Scale bar $=10 \mu \mathrm{m}$.

415

416 Supplemental Figure S1 - Bayesian inference tree based on a 401-bp fragment of the

417 cytochrome $b$ gene from species of Trinomys. Euryzygomatomys spinosus was used as outgroup.

418 Numbers indicate Bayesian posterior probabilities $\geq 0.95$. Specimens included in this study are

419 in bold. Scale bar represents the number of substitutions per site.

420 Supplemental Figure S2 - Maximum likelihood tree based on a 401-bp fragment of the

421 cytochrome $b$ gene from species of Trinomys plus Euryzygomatomys spinosus as outgroup.

422 Numbers represent bootstrap support. Specimens included in this study are in bold. Scale bar

423 indicates the number of substitutions per site.

424 Supplemental Figure S3 - Two-dimensional PCoA ordination diagram of Trinomys species,

425 showing the similarity (or dissimilarity) between individuals. The specimens included in the

426 present study are indicated by their deposit numbers.

427 Supplemental Figure S4 - Karyotype of a female Trinomys setosus setosus $(2 \mathrm{n}=56, \mathrm{FN}=108)$,

428 from Morro do Pilar, Minas Gerais state, after Giemsa staining. Scale bar $=10 \mu \mathrm{m}$. 
Figure 1 (on next page)

Sample sites of the specimens used in this study against the known range of Trinomys species.

For detailed references on spatial data downloaded from IUCN for each species, see

Supplemental Material (Part A) . Distribution of (A) T. dimidiatus, T. paratus, T. setosus, and $T$, yonenagae, and (B) T. albispinus, T. eliasi, T. gratiosus, T. iheringi, T. mirapitanga, and $T$. moojeni. Triangles represent our specimens and circles indicate the specimens whose mitochondrial sequences were retrieved from GenBank. 


\section{Figure 2}

Collapsed bayesian inference tree based on a 401-bp fragment of the cytochrome $b$ gene from species of Trinomys.

Euryzygomatomys spinosus was used as outgroup. Collection sites: (A) Serra do Caraça Private Reserve/MG, (B) Morro do Pilar/MG, (C) Serro/MG, (D) São Gonçalo do Rio Abaixo/MG. Numbers represent Bayesian posterior probabilities $\geq 0.95$. Specimens included in this study are in bold. See Supplemental Fig. S1 for specimens details of the collapsed branches. Scale bar represents the number of substitutions per site. 


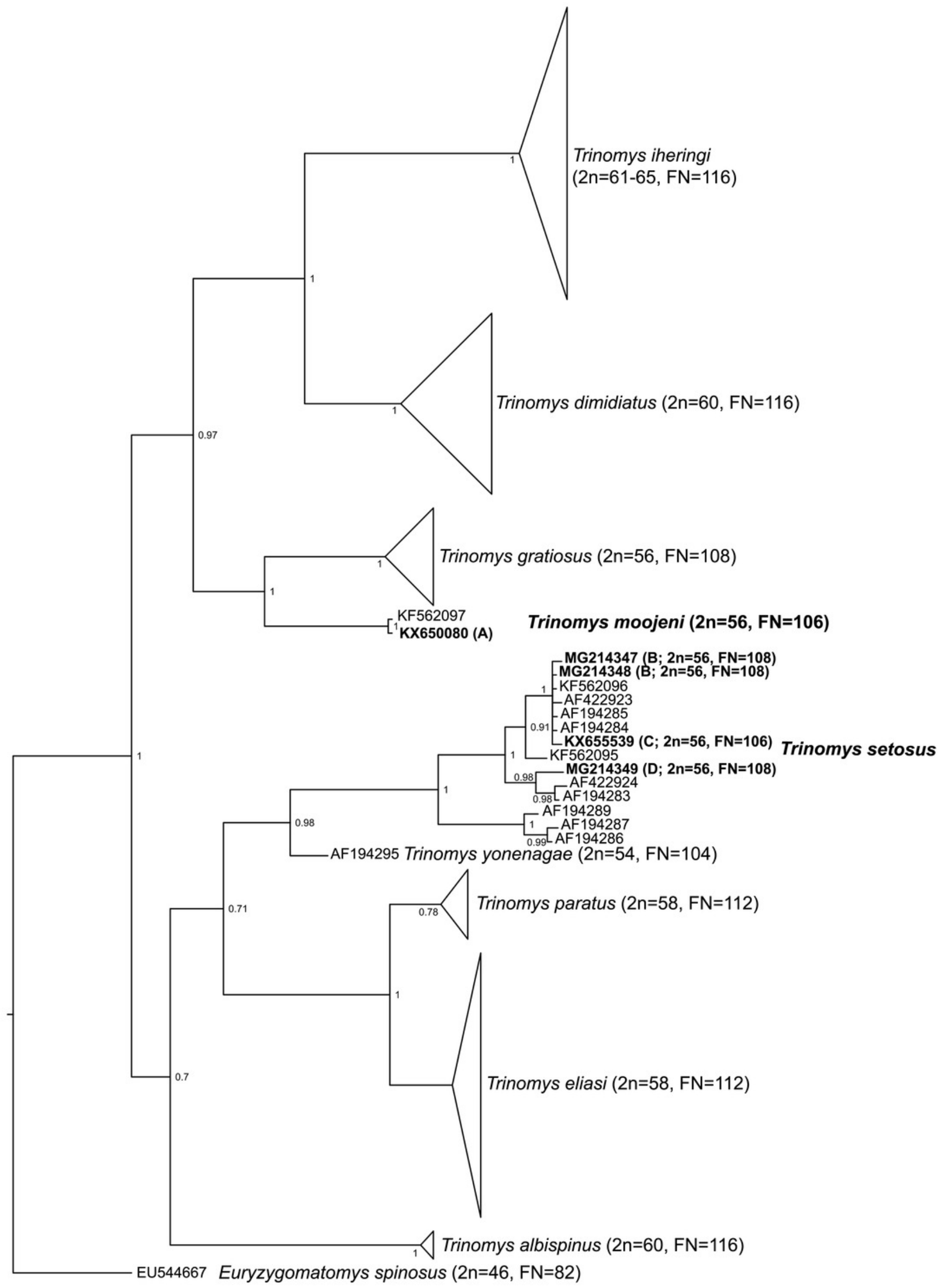

PeerJ reviewing PDF | (2018:02:25803:2:0:CHECK 2 Jul 2018) 
Figure 3

Karyotypes of a female Trinomys moojeni $(2 \mathrm{n}=56, \mathrm{FN}=106)$.

Karyotypes of a female Trinomys moojeni $(2 \mathrm{n}=56, \mathrm{FN}=106)$ from Serra do Caraça Private Reserve, Minas Gerais State, after (A) GTG- and (B) CBG-banding. Scale bar $=10 \mu \mathrm{m}$.

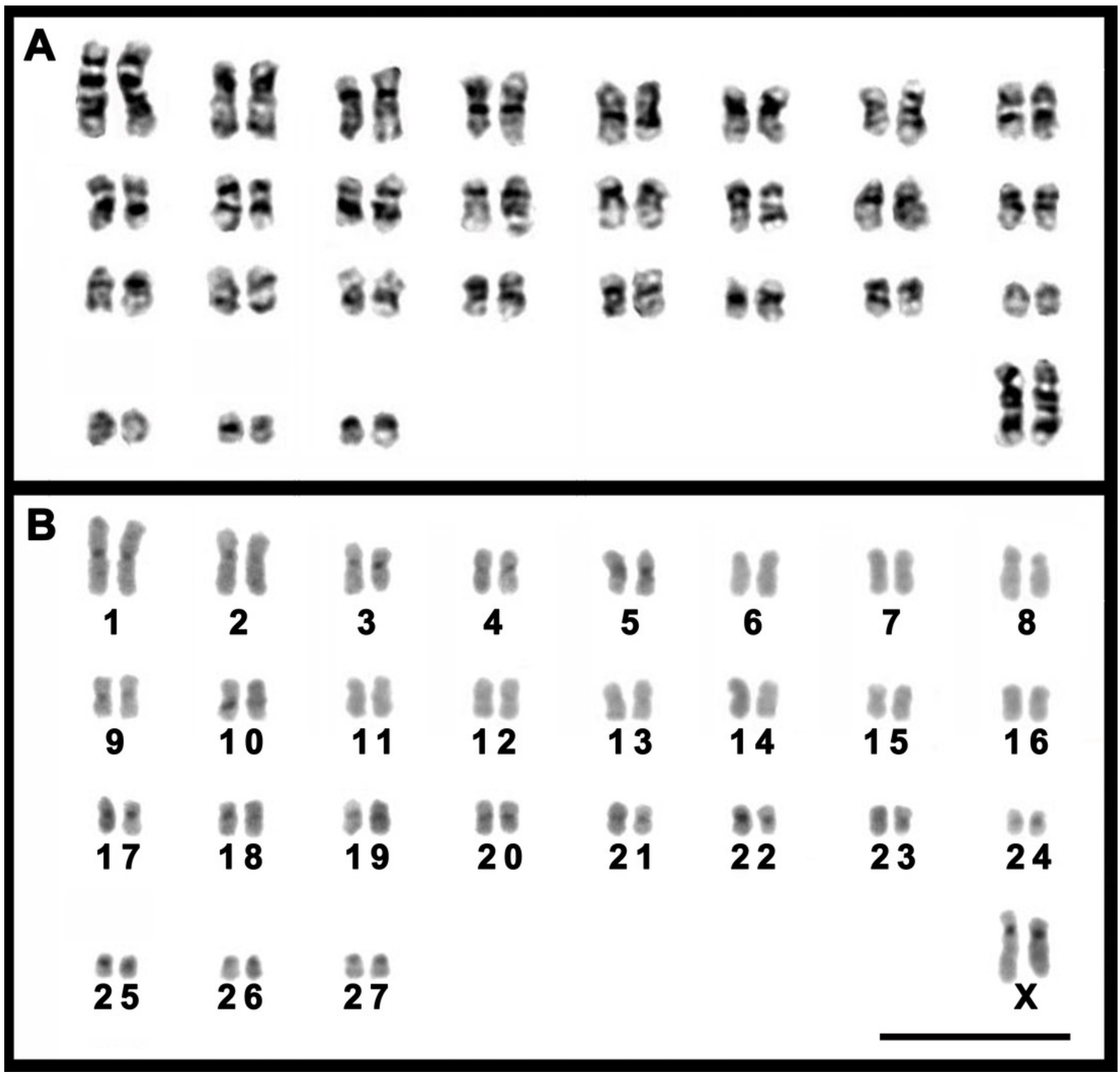


Figure 4

Karyotypes of Trinomys setosus setosus.

A female with $2 n=56, F N=106$ ( $A$ and $B$ ) from Serro, Minas Gerais state, and of a male with $2 n=56, F N=108$ (C and D) from São Gonçalo do Rio Abaixo, Minas Gerais state, after GTG- (A and $C$ ) and CBG-banding (B and D). Scale bar $=10 \mu \mathrm{m}$.

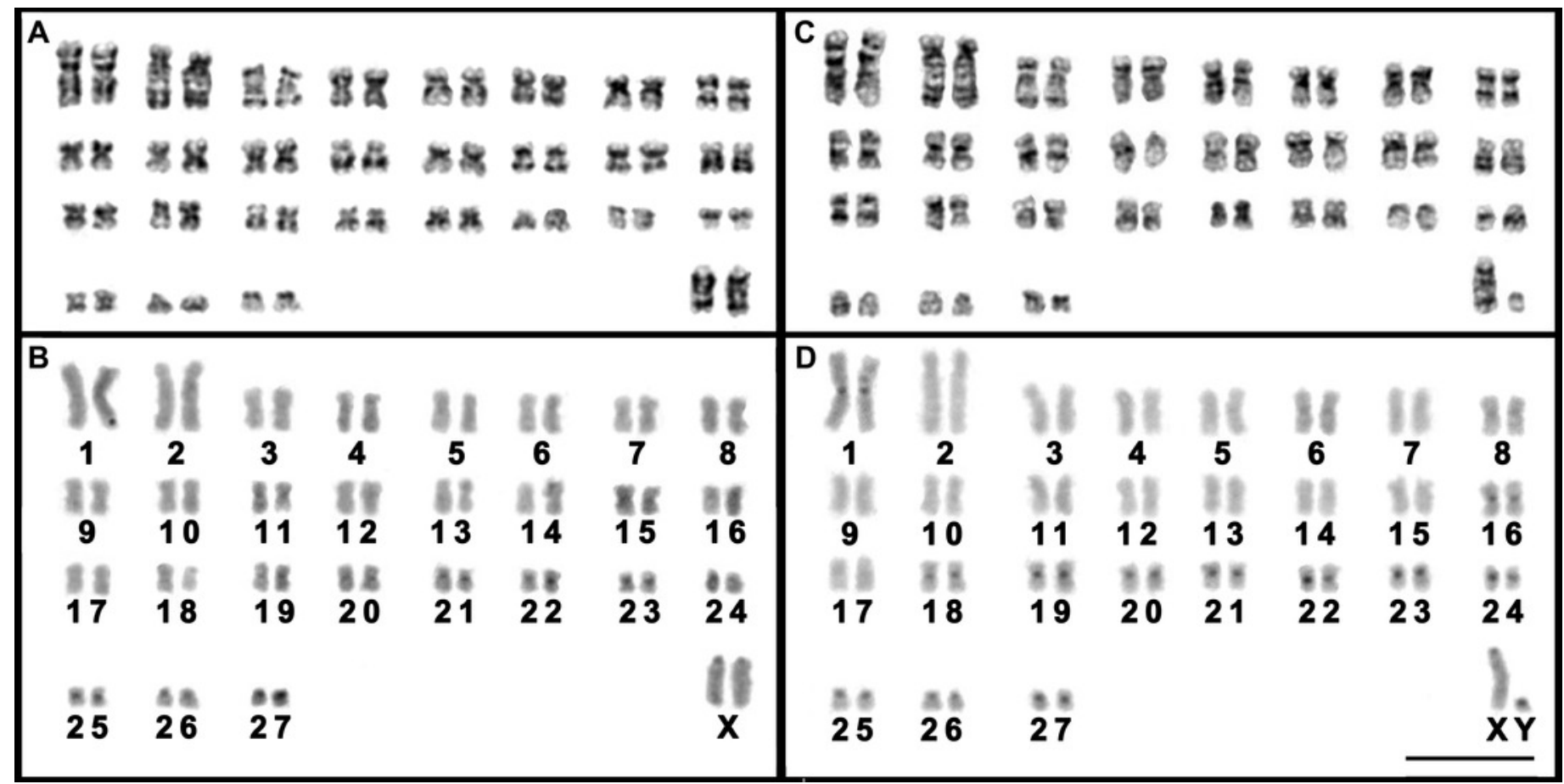


Figure 5

Comparison of GTG-banded chromosomes of Trinomys species.

Chromosomes from the left to the right: Trinomys moojeni $(2 n=56, F N=106)$, Trinomys setosus setosus $(2 \mathrm{n}=56, \mathrm{FN}=106)$, and Trinomys s. setosus $(2 \mathrm{n}=56, \mathrm{FN}=108) . *=$ centromere position. The arrows indicate possible inversion sites.

\begin{tabular}{|c|c|c|c|c|c|}
\hline 울 & ${ }^{*}{ }^{*}{ }^{*}{ }^{*}$ & $\underset{3}{8}$ & -8 & $\frac{8}{6}$ & $\begin{array}{ccc}8 & 8 & 8 \\
7 & 5 & 5\end{array}$ \\
\hline $\begin{array}{c}68 \\
8\end{array}$ & $8-\frac{8}{9}$ & $8 \underset{11}{8}$ & $-\begin{array}{r}58 \\
77\end{array}$ & $\theta_{-13}$ & $-\frac{5}{15}$ \\
\hline E $\mathbb{E}_{16} \mathrm{E}$ & $\begin{array}{rrr}8 & 4 & \\
17 & 18 & 18\end{array}$ & $\begin{array}{rrr}8 & \approx & \\
18 & 17 & 17\end{array}$ & \& 8 8 & $\begin{array}{lll}8 & \approx & \\
22 & 20 & 20\end{array}$ & $\begin{array}{ccc}3 & 4 & \text { : } \\
23 & 21 & 21\end{array}$ \\
\hline 242323 & $\Rightarrow \underset{25}{2}$ 항 & 262424 & $* * 27 * n$ & & $x$ \\
\hline
\end{tabular}




\section{Figure 6}

Cells of Trinomys species after Ag-NOR, FISH with the $45 \mathrm{~S}$ rDNA, and telomeric probe (Tel).

Metaphases of $(\mathrm{A}-\mathrm{C})$ a female $T$. moojeni $(2 \mathrm{n}=56, \mathrm{FN}=106),(\mathrm{D}-\mathrm{F})$ a female $T$. setosus setosus $(2 \mathrm{n}=56, \mathrm{FN}=106)$, and $(\mathrm{G}-\mathrm{I})$ a male $T$. s. setosus $(2 \mathrm{n}=56, \mathrm{FN}=108)$. In the insets $(\mathrm{A}, \mathrm{D}$, and G), pair 6 after Giemsa staining. Note the secondary constrictions. Scale bar $=10 \mu \mathrm{m}$. 


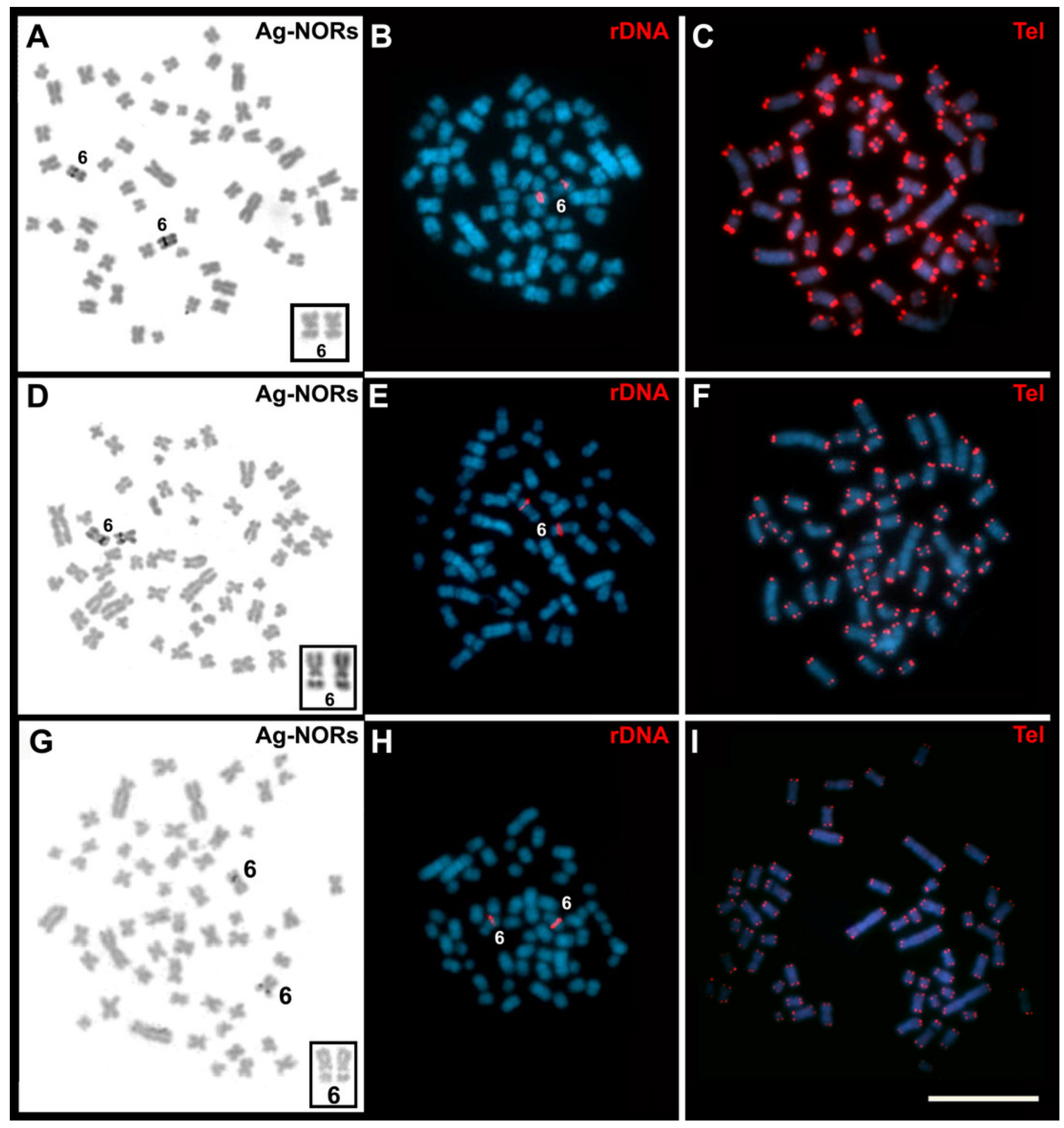


Table $\mathbf{1}$ (on next page)

Karyotypic data of species of Trinomys. 
1 Table 1. Karyotypic data of species of Trinomys.

\begin{tabular}{|c|c|c|c|}
\hline Species* & $2 n / F N$ & Banding patterns/FISH & References \\
\hline $\begin{array}{l}\text { Trinomys albispinus } \\
\text { T. a. albispinus } \\
\text { T. a. minor } \\
\text { Trinomys dimidiatus } \\
\text { Trinomys eliasi }\end{array}$ & $\begin{array}{l}60 / 116 \\
60 / 116 \\
60 / 116 \\
58 / 112\end{array}$ & $\begin{array}{l}\text { Ag-RONs } \\
\text { GTG, CBG, RBG, Ag-NORs } \\
- \\
-\end{array}$ & $\begin{array}{l}\text { Souza, Corrêa \& Pessôa (2006) } \\
\text { Leal-Mesquita et al. (1992) } \\
\text { Pessôa et al. (2005) } \\
\text { Pessôa et al. (2005) }\end{array}$ \\
\hline $\begin{array}{l}\text { Trinomys gratiosus } \\
\text { T. g. gratiosus } \\
\text { T. g. bonafidei } \\
\text { T. g. panema }\end{array}$ & $\begin{array}{r}- \\
56 / 108 \\
-\end{array}$ & $\begin{array}{l}- \\
-\end{array}$ & $\begin{array}{c}- \\
\text { Pessôa et al. (2005) } \\
-\end{array}$ \\
\hline Trinomys iheringi & $61-65 / 116$ & $\begin{array}{l}\text { GTG, CBG, RBG, Ag-NORs, FISH } \\
\text { with telomeric and rDNA probes }\end{array}$ & $\begin{array}{l}\text { Yonenaga-Yassuda et al. (1985) } \\
\text { Fagundes, Camacho \& } \\
\text { Yonenaga-Yassuda (2004) }\end{array}$ \\
\hline Trinomys mirapitanga & - & - & - \\
\hline $\begin{array}{l}\text { Trinomys moojeni } \\
\text { Trinomys paratus }\end{array}$ & $\begin{array}{l}56 / 106 \\
58 / 112\end{array}$ & CBG & $\begin{array}{l}\text { Corrêa et al. (2005) } \\
\text { Lazar et al. (2017) }\end{array}$ \\
\hline $\begin{array}{l}\text { Trinomys setosus } \\
\text { T. s. elegans } \\
\text { T. s. setosus }\end{array}$ & $\begin{array}{r}56 / 104 \\
-\end{array}$ & $\begin{array}{l}- \\
-\end{array}$ & Corrêa et al. (2005) \\
\hline Trinomys yonenagae & $54 / 104$ & GTG, CBG, RBG, Ag-NORs & Leal-Mesquita et al. (1992) \\
\hline
\end{tabular}


Table 2 (on next page)

Specimens analyzed. 
1 Table 2. Specimens analyzed.

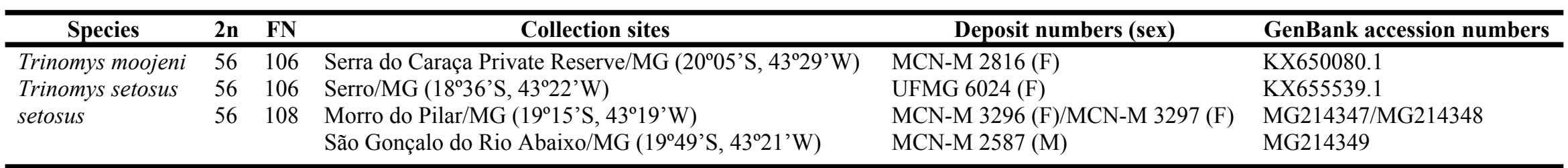

2 2n - diploid number; FN - fundamental number; M - male; F - female; MCN-M - Museu de Ciências Naturais - Pontifícia

3 Universidade Católica (PUC, Minas Gerais, Brazil); UFMG - Centro de Coleções Taxonômicas - Universidade Federal de Minas

4 Gerais (CCT-UFMG, Minas Gerais, Brazil). 